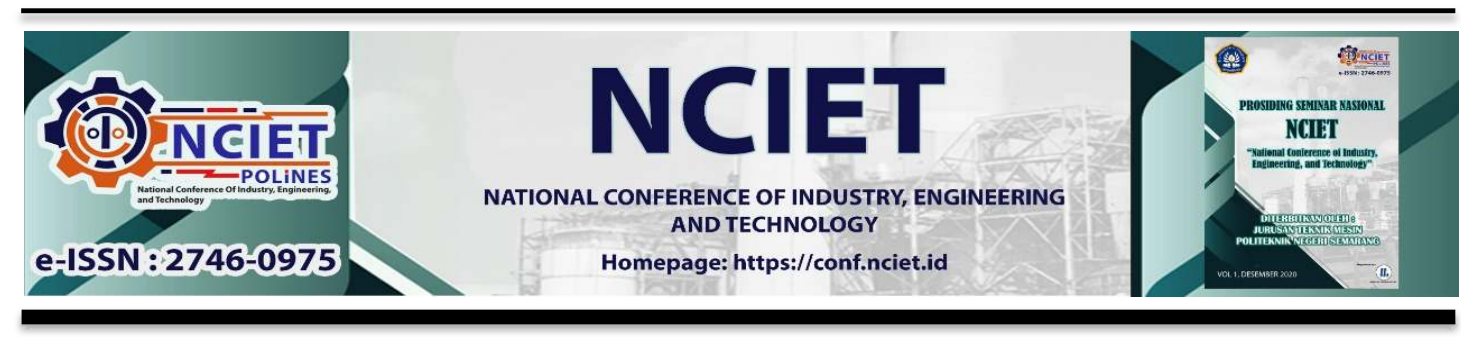

Prosiding Seminar Nasional NCIET Vol.1 (2020) B415-B422

$1^{\text {st }}$ National Conference of Industry, Engineering and Technology 2020,

Semarang, Indonesia.

\title{
ANALISIS INDEKS SAIDI, SAIFI, CAIDI DAN NON-DELIVERY ENERGY SISTEM DISTRIBUSI 20 KV PADA PT. PLN (PERSERO) AREA BALIKPAPAN PENYULANG J2
}

\author{
Yun Tonce Kusuma Priyanto ${ }^{1 *}$, Muhamad Otong ${ }^{2}$, Yanuar Mahfudz Safarudin ${ }^{3}$ \\ ${ }^{1}$ Jurusan Teknik Elektro, Institut Teknologi Kalimantan \\ Jl. Soekarno Hatta No.KM 15, Karang Joang, Balikpapan Utara, Balikpapan, 76127 \\ ${ }^{2}$ Jurusan Teknik Elektro, Universitas Sultan Ageng Tirtayasa \\ Jl. Raya Jkt Km 4, Panancangan, Cipocok Jaya, Serang, 42124 \\ ${ }^{3}$ Jurusan Teknik Mesin, Politeknik Negeri Semarang \\ J1. Prof H. Soedarto, SH, Tembalang, Semarang, 50275 \\ *E-mail: yuntonce@,itk.ac.id
}

\begin{abstract}
Abstrak
Indeks keandalan tenaga listrik menunjukkan tingkat kontinuitas suplai PLN pada suatu daerah. Indeks keandalan ini biasa disajikan dalam bentuk SAIDI, SAIFI, dan CAIDI. Nilai indeks SAIDI, SAIFI, dan CAIDI yang baik menunjukkan tingkat kontinuitas listrik yang baik ditunjukkan dalam sering atau tidaknya gangguan dan durasi ketika gangguan.

Paper ini membahas mengenai nilai indeks keandalan tenaga listrik di Sistem Distribusi $20 \mathrm{kV}$ pada PT. PLN (Persero) Area Balikpapan Penyulang J2. Hasil menunjukkan bahwa Indeks keandalan pada penyulang J2 yaitu SAIDI, SAIFI, dan CAIDI sebelum pemasangan sectionalizer berturut-turut adalah 138, 156, dan 0,88. Sedangkan kerugian enokominya adalah sebesar Rp. 736.028.800.

Kemudian pemasangan sectionalizer yang terhubung dengan penyulang J5 didapatkan indeks keandalan yang lebih baik yaitu SAIDI $=134$, SAIFI 147, dan CAIDI $=54,66$. Dan kerugian ekonomi dapat diturunkan sebesar Rp. 53.585.168. Pemasangan recloser dan LBS motorized pada penyulang $\mathrm{J} 2$ dapat memperkecil recovery time sehingga waktu padam juga dapat berkurang. Sebelum pemasangan recloser dan LBS motorized total padam pada bulan Agustus 2018 adalah sebanyak 1.782 menit dan setelah pemasangan total padamnya berubah menjadi $1.448,8$ menit. Selisih waktu padam yang diperoleh antara sebelum dan setelah pemasangan adalah 333,2 menit atau 5,55 jam atau sebanyak 19\% dari total padam sebelum pemasangan.
\end{abstract}

Kata Kunci: Jaringan Distribusi; Nilai Ekonomi; Pemadaman; SAIDI; SAIFI; CAIDI

\section{PENDAHULUAN}

Menurut Badan Pusat Statistik (BPS) Indonesia tahun 2018, Kalimantan Timur adalah salah satu provinsi yang berkontribusi besar dalam pembangunan Indonesia khususnya pada bidang ekonomi. Provinsi Kalimantan Timur memiliki sumber daya alam yang sangat berpotensi dan saat ini menjadi wilayah sentral industri. Penulis kali ini akan berfokus pada Kota Balikpapan yang menjadi salah satu kota yang ikut serta dalam pembangunan ekonomi 
Indonesia dan dirasa cukup maju dalam sisi aspek bisnis dan industrinya. Menjadi salah satu wilayah sentral industri tentunya Balikpapan membutuhkan pasokan energi energi listrik. Energi listrik menjadi kebutuhan pokok bagi penduduk Balikpapan dan jumlah permintaanya selalu bertambah tiap tahun. Seiring bertambahnya kebutuhan energi listrik ini, maka dibutuhkan peningkatan pada sektor pembangkit listrik dan pengembangan infrastruktur, sehingga proses transfer energi listrik dapat berjalan dengan baik. Namun pada kenyataannya penyaluran energi listrik masih sering mengalami gangguan dibuktikan dengan adanya pemadaman yang dampaknya dapat merugikan konsumen dan juga produsen tenaga listrik, hal ini dapat dirasakan sendiri oleh penulis.

Menanggapi hal tersebut penulis melakukan penelitian analisis indeks keandalan dan nilai ekonomi jaringan distribusi di penyulang J2. Dalam penelitian ini digunakan beberapa indeks keandalan yaitu SAIDI (System Average Intterruption Duration Index), SAIFI (System Average Interruption Frequency Index), dan CAIDI (Customer Average Interruption Duration Index) sebagai metode analisis evaluasi.

Kemudian untuk analisis aspek ekonomi akan menggunakan analasis data Non-Delivery Energy dalam satu tahun. Data ini didapatkan dari pengumpulan data yang dilakukan pada PT. PLN Persero Area Balikpapan. Selain itu, akan diberikan beberapa solusi yang bertujuan untuk memperbaiki nilai keandalan dan aspek ekonomi sehingga kedepannya sistem kelistrikan wilayah Kalimantan Timur khususnya area Balikpapan menjadi lebih handal.

\section{METODE PENELITIAN}

Metode yang digunakan sebagai analisis indeks keandalan adalah SAIDI, SAIFI, dan CAIDI. Sedangkan analisis aspek ekonomi menggunakan perhitungan data energi tak tersalurkan dikalikan dengan tarif dasar listrik yang berlaku. Untuk penjelasan mengenai indeks keandalan dan aspek ekonomi akan dijelaskan lebih lanjut dibawah ini :

Indeks Keandalan

Terdapat beberapa indeks keandalan dalam sistem tenaga listrik, dalam penelitian ini hanya digunakan tiga indeks keandalan saja karena indeks keandalan yang lain hanya menggunakan jenis gangguan yang bersifat sementara.

1. SAIDI (System Average Interruption Duration Index)

SAIDI merupakan nilai indeks rata-rata durasi atau lamanya gangguan pada sistem. SAIDI adalah durasi rata-rata interupsi atau gangguan per konsumen sepanjang tahun. Ini adalah rasio durasi gangguan tahunan (berkelanjutan) terhadap jumlah konsumen. 
Jika durasi ditentukan dalam hitungan menit, SAIDI dinyatakan dalam menit gangguan yang dirasakan konsumen.

$$
S A I D I=\frac{\text { Durasi padam } \times \text { Pelanggan padam }}{\text { Jumlah total pelanggan }} \mathrm{jam} / \mathrm{plg} / \mathrm{tahun}
$$

2. SAIFI (System Average Interruption Frequency Index)

SAIFI merupakan nilai indeks rata-rata frekuensi gangguan pada sistem. SAIFI adalah rata-rata jumlah interupsi atau gangguan yang berkelanjutan per konsumen sepanjang tahun. Ini adalah rasio jumlah interupsi atau gangguan tahunan terhadap jumlah konsumen.

$$
S A I F I=\frac{\text { Jumlah padam } x \text { Pelanggan padam }}{\text { Jumlah total pelanggan }} \mathrm{kali} / \mathrm{plg} / \text { tahun }
$$

\section{CAIDI (Consumer Average Interruption Duration Index)}

CAIDI merupakan indeks durasi atau lamanya gangguan rata-rata bagi konsumen yang terkena gangguan tersebut. CAIDI adalah durasi atau lamanya gangguan rata-rata, dihitung berdasarkan jumlah gangguan berkelanjutan dalam setahun. Ini adalah rasio dari total durasi gangguan terhadap jumlah gangguan selama tahun tersebut.

$$
\begin{gathered}
C A I D I=\frac{\text { Total durasi gangguan berkelanjutan dalam setahun }}{\text { Jumlah total gangguan }} / \mathrm{jam} \\
\text { atau, } \\
C A I D I=\frac{S A I D I}{S A I F I} / \mathrm{jam}
\end{gathered}
$$

\subsection{Aspek Ekonomi}

Analisis aspek ekonomi dilakukan dengan menggunakan data energi tak tersalurkan dalam kurun waktu tertentu, dimana pada penelitian ini digunakan data selama satu tahun selanjutnya dikalikan dengan tarif dasar listrik yang berlaku.

Kerugian titik beban $=\mathrm{N}_{\mathrm{DE}} \mathrm{x}$ TDL

\section{Keterangan persamaan :}

$\mathrm{N}_{\mathrm{DE}} \quad=$ Jumlah energi yang tak tersalurkan dalam durasi waktu tertentu

TDL = Tarif dasar listrik yang berlaku, sesuai dengan Peraturan Menteri

Energi Sumber Daya dan Mineral Tahun 2014 


\section{HASIL DAN PEMBAHASAN}

Dari penelitian yang dilakukan, diketahui bahwa Indeks keandalan pada penyulang J2 yaitu SAIDI, SAIFI, dan CAIDI berturut-turut adalah 138, 156, dan 0,88. Sedangkan kerugian enokominya adalah sebesar Rp. 736.028.800. Oleh karena itu dilakukan beberapa upaya guna meningkatkan keandalannya, berikut adalah penjelasannya :

\subsection{Pemasangan Sectionalizer}

Upaya perbaikan ini adalah dengan memasang Load Break Switch (LBS) sebagai sectionalizer dengan penyulang lain sehingga bentuk jaringan distribusinya menjadi jaringan interkoneksi. Pemasangan sectionalizer tidak bisa sembarangan yaitu harus memperhatikan karakteristik jaringan sehingga dengan pemasangan tersebut tidak akan menimbulkan kerugian lain yang makin merugikan. Analisis pemasangan ini dilakukan dengan memperhatikan Single Line Diagram (SLD) dari penyulang.

Dalam hal ini sectionalizer akan dipasang dari penyulang J2 ke penyulang J5. Jaringan distribusi penyulang $\mathrm{J} 5$ memiliki karakteristik yang hampir mirip dari penyulang $\mathrm{J} 2$ yaitu dalam hal panjang jaringan dan beban pelanggan. LBS motorized sebagai sectionalizer ditempatkan di depan kantor PT. PLN (Persero) Rayon Balikpapan Utara. Oleh karena itu LBS ini dinamakan dengan $L B S$ MTZ PLN RBU, dan pemasangannya dapat dilihat pada $S L D$ yang ada pada gambar 3.1 . 


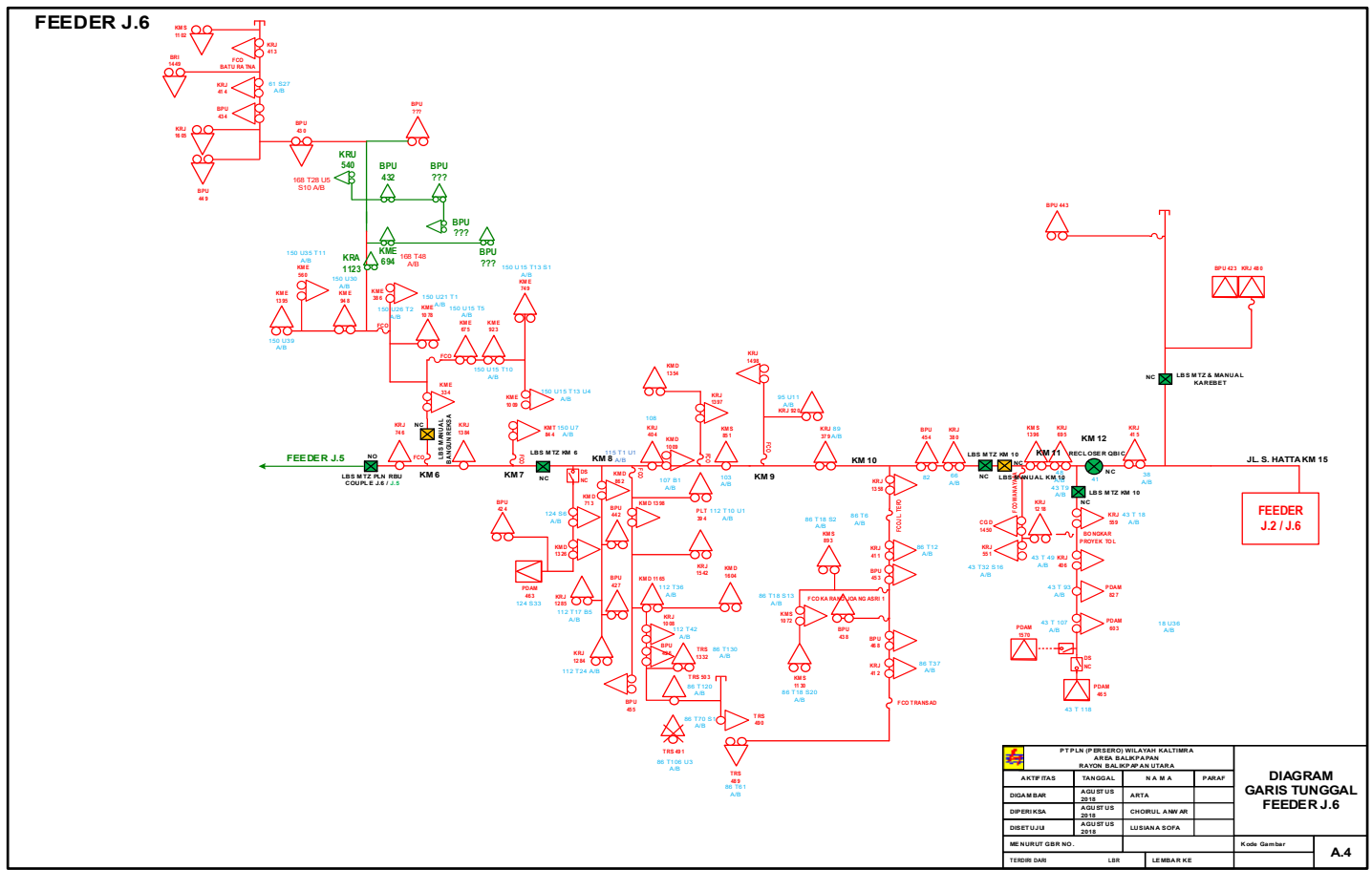

Gambar 3.1 Single Line Diagram Penyulang J2 dengan Pemasangan Sectionalizer

\subsection{Pemasangan Recloser dan LBS Motorized}

Upaya perbaikan selain dengan pemasangan sectionalizer antar jaringan adalah dengan pemasangan recloser dan load break switch (LBS) pada jaringan itu sendiri. PT. PLN (Persero) tengah berupaya untuk mengganti recloser dan $L B S$ manual menjadi recloser dan LBS motorized. Hal ini dikarenakan recloser dan LBS motorized memiliki kemudahan dalam pengoperasian dan recovery time yang lebih singkat dibandingkan dengan recloser dan $L B S$ manual.

Dari data perbandingan gangguan dan recovery time antara recloser dan $L B S$ manual dengan motorized pada bulan Agustus 2018 pada tabel 3.1 dan tabel 3.2, dapat dilihat bahwa pada satu kali gangguan dengan beban yang sama diperoleh rata - rata penghematan waktu sebanyak 30 menit untuk penormalan. Dengan menggunakan persamaan pada analisis aspek ekonomi, didapatkan waktu rata-rata penghematan sebanyak 30 menit. Waktu rata-rata penghematan ini hanya diambil pada gangguan dengan durasi di atas 60 menit yang biasa disebut dengan gangguan tidak disengaja yang ditunjukkan pada tabel 3.1 dan 3.2 dengan diberi tanda berwarna merah. Gangguan tidak disengaja biasanya disebabkan oleh pohon tumbang, binatang, dan berbagai gangguan lain. Untuk waktu padam dengan durasi di bawah 
60 menit, waktu padam tersebut disebabkan oleh gangguan yang bersifat sementara atau sistem buka/tutup saluran yang dilakukan oleh operator PT. PLN (Persero).

Tabel 3.1 Gangguan dan Recovery Time LBS Manual

\begin{tabular}{ccccccc}
\hline No & Tanggal & Waktu & Waktu & Waktu & $\begin{array}{c}\text { Lama } \\
\text { Padam } \\
\text { Putus }\end{array}$ & $\begin{array}{c}\text { Lepas } \\
\text { (MW) }\end{array}$ \\
\hline 1 & $02 / 08 / 2018$ & - & $10: 14$ & $14: 39$ & 265,2 & 1,9 \\
2 & $06 / 08 / 2018$ & $09: 18$ & - & $09: 18$ & 1,8 & 1 \\
3 & $06 / 08 / 2018$ & $09: 18$ & - & $09: 20$ & 1,8 & 0,7 \\
4 & $07 / 08 / 2018$ & $14: 54$ & - & $14: 54$ & 37,8 & 1,2 \\
5 & $07 / 08 / 2018$ & $14: 54$ & - & $14: 58$ & 4,2 & 0,7 \\
6 & $07 / 08 / 2018$ & 14.54 & - & 15.32 & 37,8 & 0,70 \\
7 & $15 / 08 / 2018$ & - & $09: 49$ & $13: 37$ & 228 & 1,8 \\
8 & $15 / 08 / 2018$ & - & $09: 49$ & $13: 37$ & 228 & 2 \\
9 & $15 / 08 / 2018$ & - & $04: 49$ & $13: 39$ & 228 & 1 \\
10 & $20 / 08 / 2018$ & - & 14.28 & $19: 30$ & 301,8 & 0,2 \\
11 & $25 / 08 / 2018$ & 13.44 & - & 15.40 & 115,8 & 0,5 \\
12 & $25 / 08 / 2018$ & - & 13.44 & 15.40 & 115,8 & 1 \\
13 & $25 / 08 / 2018$ & - & 13.44 & 16.38 & 174 & 1 \\
14 & $28 / 08 / 2018$ & - & 10.43 & 11.25 & 42 & 2 \\
\hline & & & & & & \\
\hline
\end{tabular}

Tabel 3.2 Gangguan dan Recovery Time LBS Motorized

\begin{tabular}{ccccccc}
\hline No & Tanggal & $\begin{array}{c}\text { Waktu } \\
\text { Putus }\end{array}$ & $\begin{array}{c}\text { Waktu } \\
\text { Lepas }\end{array}$ & $\begin{array}{c}\text { Waktu } \\
\text { Masuk }\end{array}$ & $\begin{array}{c}\text { Lama } \\
\text { Padam } \\
\text { (menit) }\end{array}$ & $\begin{array}{c}\text { Beban } \\
\text { (MW) }\end{array}$ \\
\hline 1 & $02 / 08 / 2018$ & - & $10: 14$ & $14: 09$ & 235,2 & 1,9 \\
\hline 2 & $06 / 08 / 2018$ & $09: 18$ & - & $09: 18$ & 0,9 & 1 \\
3 & $06 / 08 / 2018$ & $09: 18$ & - & $09: 19$ & 0,9 & 0,7 \\
4 & $07 / 08 / 2018$ & $14: 54$ & - & $14: 54$ & 7,8 & 1,2 \\
5 & $07 / 08 / 2018$ & $14: 54$ & - & $14: 58$ & 2,8 & 0,7 \\
6 & $07 / 08 / 2018$ & 14.54 & - & 15.02 & 7,8 & 0,70 \\
7 & $15 / 08 / 2018$ & - & $09: 49$ & $13: 37$ & 198 & 1,8
\end{tabular}




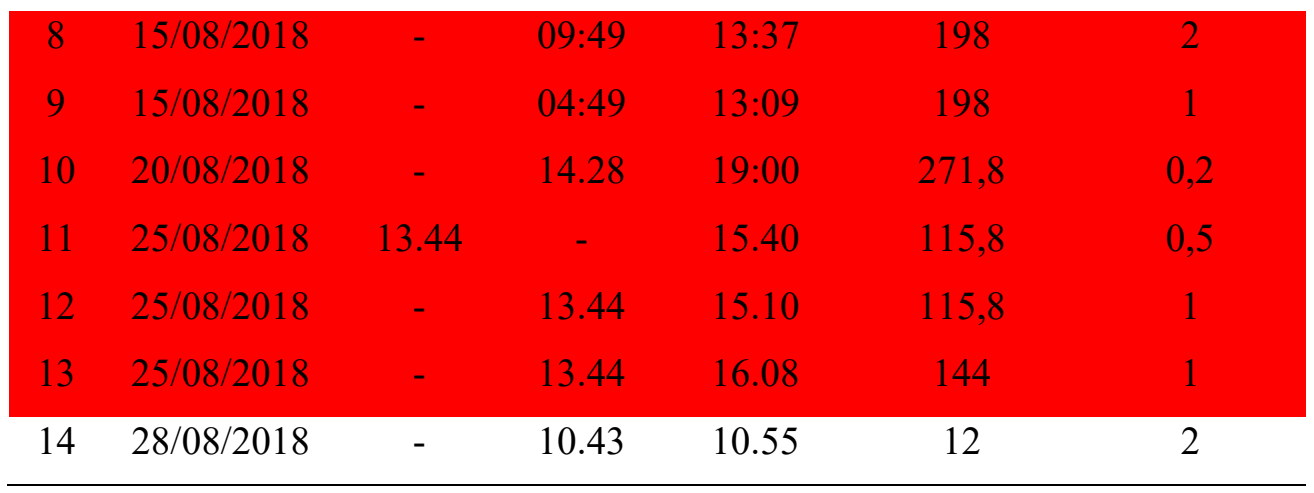

\section{KESIMPULAN}

Dari analisis yang telah dilakukan pada penyulang J2 jaringan distribusi $20 \mathrm{kV}$ PT. PLN (Persero) Area Balikpapan dapat disimpulkan bahwa :

1. Indeks keandalan pada penyulang J2 yaitu SAIDI, SAIFI, dan CAIDI sebelum pemasangan sectionalizer berturut-turut adalah 138, 156, dan 0,88. Sedangkan kerugian enokominya adalah sebesar Rp. 736.028.800.

2. Upaya perbaikan yang dilakukan pada penyulang J2 adalah dengan pemasangan sectionalizer dan pemasangan recloser dan LBS motorized. Pemasangan sectionalizer yang terhubung dengan penyulang J5 didapatkan indeks keandalan yang lebih baik yaitu $S A I D I=134, S A I F I$ 147, dan $C A I D I=54,66$. Dan kerugian ekonomi dapat diturunkan sebesar Rp. 53.585.168. Pemasangan recloser dan LBS motorized pada penyulang J2 dapat memperkecil recovery time sehingga waktu padam juga dapat berkurang. Sebelum pemasangan recloser dan LBS motorized total padam pada bulan Agustus 2018 adalah sebanyak 1.782 menit dan setelah pemasangan total padamnya berubah menjadi $1.448,8$ menit. Selisih waktu padam yang diperoleh antara sebelum dan setelah pemasangan adalah 333,2 menit atau 5,55 jam atau sebanyak 19\% dari total padam sebelum pemasangan.

3. Setelah dilakukan perbaikan, maka energi yang taktersalurkan dapat diperkecil sehingga kerugian biaya juga dapat dikurangi. Hal ini menunjukkan bahwa penyulang J2 menjadi lebih handal. Sebelum dilakukan perbaikan, kerugian pada PT. PLN (Persero) adalah sebesar Rp. 736.028.800 sedangkan dengan setelah perbaikan, banyaknya kerugian berubah menjadi Rp. 682.443.632. Perbaikan ini dapat mengurangi kerugian PT. PLN (Persero) sebesar Rp 53.585.168 atau sebesar 8\% dari total kerugian sebelum perbaikan. 


\section{DAFTAR PUSTAKA}

Brown, R. E., "Electric Prower Distribution Reliability", CRC Press, New York, Chapter 2, 2009.

Erhaneli, "Evaluasi Keandalan Sistem Distribusi Tenaga Listrik Berdasarkan Indeks Keandalan SAIDI dan SAIFI pada PT. PLN (Persero) Rayon Bagan Batu Tahun 2015", Jurnal Tugas Akhir Institut Teknologi Padang, 2016.

Gonen, T., "Reliability Electric Power Distribuion System Engineering”, McGraw-Hill, United States of America, 1986.

IEEE Std. 1366-2012, IEEE Guide for Electric Power Distribution Reability Indices.

ISSN.0126-2319, Indikator Ekonomi : Buletin Statistik Bulanan, Badan Pusat Statistik, 2018.

Praditama, F., "Analisis Keandalan dan Nilai Ekonomi di Penyulang Pujon PT. PLN (Persero) Area Malang”, Jurnal Tugas Akhir Universitas Brawijaya, 2014.

Putri, Wayan Madina O., "Analisis Aspek Ekonomi dari Keandalan Sistem Distribusi $20 \mathrm{kV}$ pada PT. PLN (Persero) Area Balikpapan Gardu Induk Karang Joang Penyulang J4", Jurnal Tugas Akhir Institut Teknologi Kalimantan, 2017.

Short, T., Electric Power Distribution Handbook, CRC Press, London, 2004, Chapter $1-3.2$

Suhadi, T. W., "Teknik Distribusi Tenaga Listrik", Direktorat Pembinaan Sekolah Menengah Kejuruan, Direktorat Jenderal Manajemen Pendidikan Dasar dan Menengah, Departemen Pendidikan Nasional, Jilid 1, 2008.

SPLN 59-1985, Keandalan pada Sistem Distribusi $20 \mathrm{kV}$ dan $6 \mathrm{kV}$.

Westinghouse, Electrical Transmission and Distribution Reference Book, Oxford \& IBH Publishing Company, New Delhi 1950. 